\title{
Análise dos impactos socioambientais decorrentes do prolongamento da Avenida João Paulo II no Bairro da Guanabara (Belém/PA)
}

Empreendimentos rodoviários têm sido um dos maiores geradores de mudanças ambientais, assim como a construção de rodovias. Nesse contexto, a utilização de ferramentas do geoprocessamento auxilia na avaliação da prescrição de um diagnóstico ambiental para aplicação de práticas que atenuem os problemas enfrentados por essas. O presente artigo teve o objetivo identificar junto à comunidade local, as possíveis transformações paisagísticas e impactos socioambientais com a implementação do prolongamento da Avenida João Paulo II, ao entorno do bairro Guanabara, Ananindeua (PA), situado na Zona Metropolitana de Belém. $\mathrm{O}$ tratamento e análise dos dados das imagens em todas as etapas para confecção dos mapas foram realizados pelo software QGis 2.18. Todos os levantamentos quantitativos e qualitativos sobre a percepção das alterações no ambiente pelos moradores foram in loco. Constatou-se que $95 \%$ dos residentes apontaram fortemente o impacto na vegetação, o que contribuiu para $60 \%$ dos entrevistados sentissem mudanças térmicas após a construção da rodovia no recinto, visto que a avenida é local de escoamento de cargas. Dados confirmados na exposição dos mapas. Contudo, considerou-se positivo o prolongamento da avenida melhoria na infraestrutura por parte dos entrevistados. Logo, é necessário um melhor planejamento na criação de vias em vista a minimização de impactos ambientais compreendendo todas as fases de implementação da obra.

Palavras-chave: Desenvolvimento Urbano; Urbanização; Infraestrutura; Geoprocessamento; Belém.

\section{Analysis of socio-environmental impacts resulting from the extension of Avenida João Paulo II in Bairro da Guanabara (Belém/PA)}

\begin{abstract}
Road developments have been a major driver of environmental change, as has highway construction. In this context, the use of geoprocessing tools assists in the evaluation of the prescription of an environmental diagnosis for the application of practices that mitigate the problems faced by these. This article aimed to identify with the local community, the possible landscape changes and socio-environmental impacts with the implementation of the extension of Avenida João Paulo II, around the Guanabara neighborhood, Ananindeua (PA), located in the Metropolitan Area of Belém. The processing and analysis of image data at all stages for making the maps were performed using the QGis 2.18 software. All quantitative and qualitative surveys on the perception of changes in the environment by residents were in loco. It was found that $95 \%$ of the residents strongly pointed out the impact on vegetation, which contributed to $60 \%$ of the interviewees feeling thermal changes after the construction of the road in the enclosure, since the avenue is a place for cargo flow. Data confirmed in the map display. However, the extension of the avenue to improve infrastructure by the interviewees was considered positive. Therefore, it is necessary to better plan the creation of roads in order to minimize environmental impacts, including all phases of implementation of the work.
\end{abstract}

Keywords: Urban development; Urbanization; Infrastructure; Geoprocessing; Belém.

Topic: Geodésia, Cartografia e Sensoriamento Remoto

Reviewed anonymously in the process of blind peer
Received: 09/08/2020

Approved: 20/11/2020
Leandro Marques Torres

Universidade Federal Rural da Amazônia, Brasil

http://lattes.cnpq.br/2678860527695504

leandrotorres15@yahoo.com.br

\section{Sarah Dias Azevedo}

Universidade Federal Rural da Amazônia, Brasil

http://lattes.cnpq.br/7721203184014688

leandrotorres15@yahoo.com.br

Paulo Rick Soares Rodrigues

Universidade Federal Rural da Amazônia, Brasil

http://lattes.cnpq.br/4163157291878644

http://orcid.org/0000-0003-2016-6537

leandrotorres15@yahoo.com.br

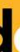

DOI: 10.6008/CBPC2318-3055.2020.003.0001
Débora Prissila Reis Sandim (it)

Universidade Federal Rural da Amazônia, Brasil

http://lattes.cnpq.br/4062780875449217

http://orcid.org/0000-0002-7391-1249

leandrotorres15@yahoo.com.br

Cézar Di Paula da Silva Pinheiro

Instituto Tecnológico Vale, Brasil

http://lattes.cnpq.br/9477837707374728

http://orcid.org/0000-0003-3946-2379

leandrotorres15@yahoo.com.br
Referencing this:

TORRES, L. M.; AZEVEDO, S. D.; RODRIGUES, P. R. S.; SANDIM, D. P. R.; PINHEIRO, C. P. S.. Análise dos impactos socioambientais decorrentes do prolongamento da avenida João Paulo II no Bairro da Guanabara (Belém/PA). Engineering Sciences, v.8, n.3, p.1-9, 2020. DOI: http://doi.org/10.6008/CBPC2318-3055.2020.003.0001 


\section{INTRODUÇÃO}

As mudanças sucedidas nas áreas urbanas da Região Metropolitana de Belém (RMB) colaboraram não apenas para a sua ocupação, por meio do entendimento das diversas formas de apropriação, assim como, acarretou um acentuado processo de degradação dos ambientes naturais (BAHIA et al., 2011). Contudo, existe na região uma negligência por parte dos governos nas questões da estruturação urbana, mesmo que está sendo considerada imprescindível na implementação estratégias para o desenvolvimento sustentável (PEREIRA et al., 2016).

A ausência de planejamento urbano desencadeia em relação conflituosa entre homem e natureza, ocasionando o comprometimento da vegetação, a qualidade da água, entre outras condições que acarretam uma baixa qualidade de vida a população na região. A desordem urbana e o excesso de veículos na capital paraense causam perdas de bens de acesso ou serviços, desse modo, a mobilidade é essencial para que se conserve o desenvolvimento e o nível de progresso (SOUSA et al., 2018)

As alterações no meio ambiente, independentemente de sua intensidade, exigem medidas preventivas, visto que, não é possível modificar o meio sem afetar a relação homem natureza (SOUSA et al., 2018). De fato, o desenvolvimento de um projeto de expansão viária, mesmo com os benéficos sociais e econômicos que pode ocasionar, traz consigo também uma serie de potenciais danos ao meio ambiente. Alguns desses impactos que podem ser citados são: o desmatamento, a perda da diversidade biológica, a alteração do sistema natural de drenagem e a degradação do solo, sendo ocasionadas pelo abandono ou interrupções da obra; e as emissões de gases poluentes e contaminações por resíduos sólidos, comuns nas áreas de construção civil. Devido aos diversos danos gerados, tem-se observado a necessidade de compensação das áreas afetadas, visto que os danos são previsíveis e de grande repercussão ao meio ambiente (VASEEN JÚNIOR, 2013).

Os impactos decorrentes de obras de expansão viária começam na fase de planejamento e prolongam-se até a fase de implementação e operacional. Os estudos de impacto ambiental no Brasil ainda são poucos no que tange a fase de operação de obras rodoviárias, em face de ser haver poucas ou nenhuma exigência segundo a legislação, mesmo está sendo uma fase com prazo de duração indeterminado, o que inclui os impactos gerados por ela (BANDEIRA et al., 2004).

Quando não há o dimensionamento correto dos impactos potenciais decorrentes desse tipo de obras, pode ocorrer a geração de impactos irreversíveis de natureza física, biótica e/ou antrópica. Uma identificação e um dimensionamento preciso dos impactos ambientais é fundamental para a proposta de ações de controle, mitigação e/ou compensação dos negativos e potencialização de impactos positivos. No último século os empreendimentos rodoviários tem sido um dos maiores geradores de mudanças no meio ambiente, visto que, transformar o meio natural em um sistema artificial, agindo com grande intensidade nos diferentes processos de desenvolvimento, assim como a construção de rodovias faz parte dos elementos que mais continuem para o processo de fragmentação dos habitats (SILVA et al., 2013).

Nesse contexto, a utilização de ferramentas do geoprocessamento auxilia na avaliação da prescrição 
de um diagnóstico ambiental para aplicação de práticas que atenuem os problemas enfrentados por essas. A confecção de mapas sobre uso e ocupação do solo tem importância nas análises e entendimentos das transformações em áreas degradadas. Assim, cede parâmetros em atribuir diagnósticos ambientais para a mitigação dos impactos negativos na localidade examinada (ANJOS, 2017).

Nesse sentido, o presente artigo teve o objetivo identificar junto à comunidade local, as possíveis transformações paisagísticas e impactos socioambientais com a implementação do prolongamento da Avenida João Paulo II, ao entorno do bairro Guanabara, Ananindeua (PA), situado na Zona Metropolitana de Belém por meio de questionários aplicados e utilização de programas geo-referenciadores que cedem melhores concepções dos problemas discutidos. Assim como a confecção de um diagnóstico ambiental que auxilie nas propostas mitigadores de impactos na região.

\section{MATERIAIS E MÉTODOS}

A área de estudo está localizada no prolongamento da Avenida João Paulo II, mais especificamente no trecho que corta o bairro da Guanabara, entre os municípios de Belém e Ananindeua, coordenadas geográficas: $1^{\circ} 23^{\prime} 29^{\prime \prime S}$ de latitude Sul e $48^{\circ} 24^{\prime} 31^{\prime \prime} W$ de longitude (Figura 1 ). O prolongamento da Avenida João Paulo II engloba três bairros, afetando uma população de mais de 150 mil pessoas (SOUSA et al., 2018).

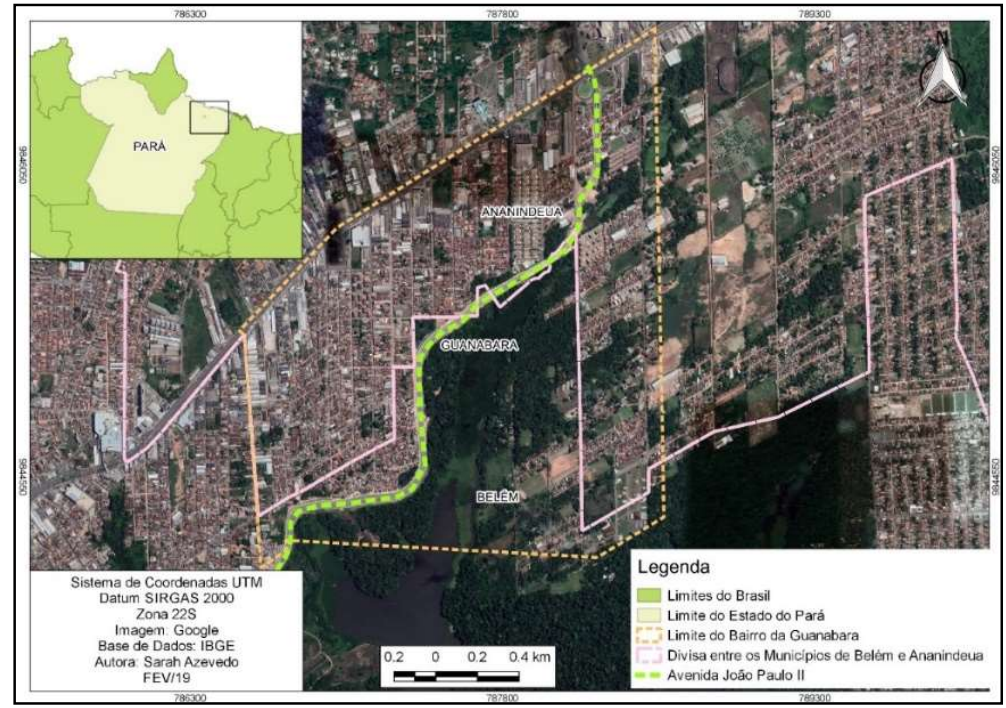

Figura 1: Localização da área de estudo.

Os pesquisadores trabalharam com dados qualitativos e quantitativos. Em um primeiro momento, com o objetivo de realizar o reconhecimento do bairro e uma primeira aproximação com os moradores afetados, foram realizadas visitas in loco. Posteriormente, 30 questionários com perguntas abertas e de múltipla escolha foram aplicados aos moradores do bairro com o objetivo de identificar os impactos por meio da percepção dos moradores.

Em um segundo momento foram confeccionados mapas de Uso e Cobertura do solo e de Temperatura da Superfície Terrestre (TST) para confirmar os resultados obtidos em campo. O tratamento e análise dos dados das imagens em todas as etapas foram realizados pelo software QGis 2.18. Na geração do mapa temático foram utilizadas imagens dos satélites Landsat 5 e Landsat 8 sensor Thematic Mapper (TM) e 
resolução espacial de 30 metros.

Com o objetivo de realizar uma análise temporal das modificações decorrente do prolongamento, estipulou-se um período de dez anos entre as duas imagens obtidas. Assim, para o satélite Landsat 5 foi selecionada uma imagem de junho de 2008, e para o Landsat 8 uma de julho de 2018.

Na realização do processo de classificação do uso e cobertura do solo, foi efetuada a composição colorida das imagens utilizando as bandas as 5/4/ 3 (Landsat 5) e 4/3/2 (Landsat 8). Após a composição foi possível visualizar três classes distintas. Senso assim, por meio do plugin semi-automatic classification foram coletadas aproximadamente 20 amostras de cada classe para gerar o mapa de classificação (Figura 2).

Para investigação dos efeitos do prolongamento sobre a temperatura de superfície foi realizada a transformação das imagens raster em valores de TST pela utilização das bandas termais 6 e 10 dos satélites Landsat 5 e 8 , respectivamente.

Inicialmente foi realizada a conversão dos níveis de cinza das bandas 6 e 10 em radiância espectral (TOA) através da equação 1 . As constantes térmicas foram adquiridas através do arquivo de metadados das imagens.

$$
L_{\lambda}=M_{L} * Q_{C a l}+A_{L}(1)
$$

Em seguida, a radiância espectral foi convertida em temperatura a partir da equação 2 .

$$
T_{s c}=\left(\frac{K_{2}}{\operatorname{In}\left(\frac{K_{1}}{L_{\lambda}}+1\right)}\right)-273.15(2)
$$

Onde:

Tsc $=$ Temperatura atmosférica (Celsius)

$\mathrm{K} 1$ = Constante de calibração 1

K2 = Constante de calibração 2

$\mathrm{L} \lambda=$ Radiância espectral $(\mathrm{W} / \mathrm{m} 2 \mathrm{sr} \mu \mathrm{m})$

Posteriormente foi realizado o cálculo do NDVI conforme as equações 3 e 4 .

Landasat 5

$$
\text { NDVI }=\frac{\text { Banda } 4-\text { Banda } 3}{\text { Banda } 4+\text { Banda } 3}(3)
$$

Landsat 8

$$
\text { NDVI }=\frac{\text { Banda } 5-\text { Band } 4}{\text { Banda } 5+\text { Ban } 4}(4)
$$

Após obter o valor do NDVI foi calculado a proporção de vegetação, equação 5 .

$$
\mathrm{P}_{\mathrm{V}}=\left(\frac{\left(\mathrm{NDVI}^{-}-\mathrm{NDVI}_{\min }\right)}{\left(\mathrm{NDVI}_{\text {máx }}-\mathrm{NDVI}_{\min }\right)}\right)^{2}
$$


Com o valor da proporção de vegetação encontrado, foi realizado o cálculo da Emissividade, equação

6.

$$
\varepsilon=\left(0.004 * \mathrm{P}_{\mathrm{v}}\right)+0.986(6)
$$

Onde:

E por fim, foi aplicada a equação TST para obter o mapa da temperatura da superfície, equação 7.

$$
\operatorname{TST}=\left(\frac{\mathrm{T}_{\mathrm{sc}}}{\left(1+\left(\frac{\mathrm{W} * \mathrm{~T}_{\mathrm{sc}}}{\mathrm{p}}\right) * \operatorname{Ln}(\epsilon)\right)}\right) \text { (7) }
$$

Onde:

TST = Temperatura da superfície terrestre;

Tsc = Temperatura atmosférica;

$$
\varepsilon=\text { Emissividade; }
$$

$\mathrm{W}=$ Comprimento de onda do brilho emitido;

$$
p=\frac{h * C}{S}(8)
$$

$\mathrm{h}=$ Constante de Planck

$\mathrm{s}=$ Constante de Boltzmann Constant

$\mathrm{C}=$ Velocidade da Luz

\section{RESULTADOS E DISCUSSÃO}

Dos 30 entrevistados $56 \%$ são mulheres e $44 \%$ homens, sendo que $85 \%$ afirmaram residir no bairro Guanabara há mais de 15 anos. Este grupo amostral tem uma percepção dos impactos ocorridos porque já vivem no local desde antes do início das obras de prolongamento da avenida. De fato, segundo os autores Abreu et al. (2015), pessoas que vivem em determinada região por um extenso período adquirem um entendimento mais vasto da realidade do local, a exemplo os riscos ambientais. Sendo assim, os anos vividos são proporcionais as sensações, sentimentos e emoções em relação ao lugar habitado.

Foi perguntado aos moradores se eles observarão melhoria na infraestrutura do bairro com o prolongamento da avenida, dentre os entrevistados, $60 \%$ responderam que houve alterações positivas na infraestrutura, sendo a pavimentação, a criação de escolas, a coleta regular de lixo, maior segurança, iluminação e melhoria no saneamento básico os principais benefícios.

Nota-se que para a maioria dos moradores a obra trouxe benefícios para a infraestrutura. De acordo com Resende (2016), as construções de avenidas ou prolongamentos contribuem para um desenvolvimento social e econômico, trazendo diversos benefícios, como o aumento da demanda de bens e serviços, da qualidade de vida de seus usuários com a facilitação do deslocamento entre as cidades, contribui, ainda, para mudanças positivas nas condições de saúde e educação da população que poderá ter acesso mais fácil aos hospitais e escolas, facilita o transporte de pessoas e de carga, além disso o comércio e o mercado imobiliário ganham, assim como a população, já que implica na evolução na qualidade de vida das pessoas.

Em relação a arborização na área, foi questionado em "uma escala de 1 a 10. Qual o nível de arborização antes e depois da obra", no qual 95\% dos entrevistados apontaram que houve diminuição na arborização. De fato, foi verificado por meio da análise temporal do uso e ocupação do solo (Figura 2) que ocorreu uma supressão da cobertura vegetal da área. Em dez anos o bairro da Guanabara perdeu cerca de 
70 hectares de vegetação (Figura 2B), representando uma queda de $20 \%$ de sua cobertura vegetal. A presença da arborização em um ambiente é de grande importância visto que diversos elementos naturais estão interligados a ela, como solo, temperatura, umidade, nebulosidade, mecanismo do vento, flora e fauna, que são responsáveis pelo conforto ambiental (MOREIRA et al., 2017). De fato, a arborização apresenta diversos benefícios ambientais, com a diminuição do componente arbóreo ocorre maior propagação de ruídos e principalmente alteração no microclima (MEIRA et al., 2015).

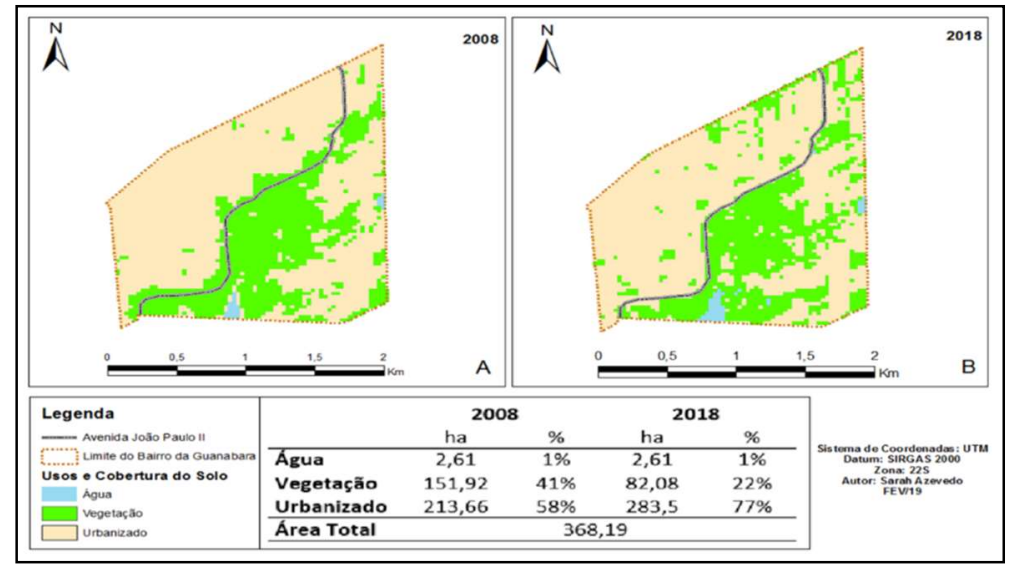

Figura 2: Uso e cobertura do solo do bairro da Guanabara para os anos de 2008 (A) e 2018 (B).

O próximo questionamento subsidiou o a pergunta anterior, assim perguntou-se "Qual a sensação térmica antes e depois do empreendimento", no qual $60 \%$ dos entrevistados responderam que sentiram um aumento na sensação térmica e $40 \%$ que continuou estável. Verificou-se a partir do mapa de temperatura da superfície terrestre o aumento na temperatura da região estudada, as temperaturas para o ano de 2008 variaram de 18ㅇ a 30 (Figura 3A), enquanto em 2018 a variação foi de 24ㅇa a 33ㅇ (Figura 3B), o que indica um aumento significativo.

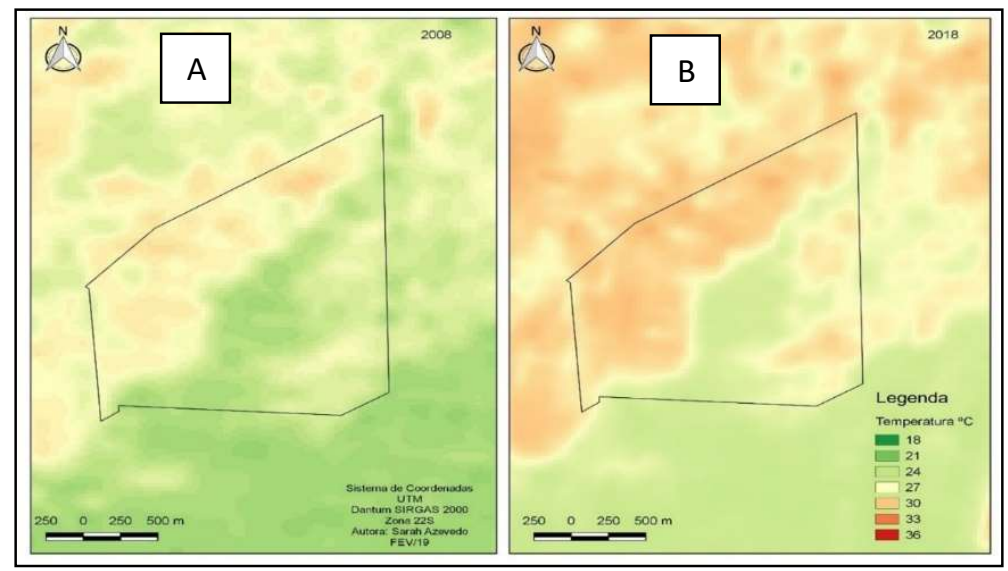

Figura 3: Temperatura de superfície terrestre do Bairro da Guanabara nos anos de 2008 (A) e 2018 (B).

O aumento da temperatura está fortemente relacionado com a diminuição da cobertura vegetal, visto que recebe radiação solar de forma direta, favorecendo assim o rápido aquecimento e o crescimento da irradiação em áreas descobertas (OLIVEIRA et al., 2018). Áreas que apresentam alta densidade florestal tendem a possuir temperaturas medias superiores as com ausência se vegetação, isso ocorre em decorrência da evapotranspiração que converte a energia solar em água no lugar de calor, deste modo, mantêm baixa a 
temperatura do ar (MASHIKI et al., 2013).

Segundo Feitosa et al. (2011), em meio as inúmeras mudanças pelas quais o espaço urbano passa, a supressão vegetal destaca-se como uma das que mais contribuem para alteração do clima nas cidades, por meio de mudanças em seus elementos meteorológicos. O autor afirma que o próprio centro urbano é um dos responsáveis pelo aquecimento, tendo como causa agravante a transição de áreas com vegetação para áreas urbanizadas, o que vem a contribuir com o decréscimo da umidade relativa do ar, devido à drenagem ou impermeabilização de áreas úmidas.

Quando questionados sobre 'Houve aumento dos ruídos durante e após a implementação da obra', 96\% dos entrevistados responderam que notaram o aumento dos ruídos, e relataram que ' $\mathrm{O}$ aumento do ruído foi maior durante a fase de desmatamento e construção', 'Os tratores trabalhavam o dia todo e incomodavam com o barulho exagerado, 'após a obra ficou um barulho maior devido ao transito de carros, mas o pior momento foi durante a construção do prolongamento'. Os autores Moura et al. (2016), avaliam que com a crescente urbanização, em uma sociedade em que a maior parte de atividades envolve a produção de ruídos, ocorre a intensificação dos ruídos que podem comprometer o bem-estar da população, que podem sofrer de estresse, irritabilidade, esgotamento psíquico e fisiológico e desenvolver problemas auditivos A grande preocupação com o controle do ruído provocados por construções de avenidas e tráfego de veículos é uma forma de assegurar a qualidade ambiental, pois a quantidade de fontes geradoras de ruído está aumentando continuamente, especialmente no meio urbano (TONIN et al., 2018).

No tocante, perguntou-se 'quais os principais transtornos durante a implementação da obra' as respostas mais frequentes foram 'Ruas fechadas, a grande presença de animais quando estavam desmatando, como cobras', 'Ruas alagadas e cheios de lamas', 'poeiras, ruídos altos devidos a perfurações e tratores, entupimentos dos bueiros e água com cor amarelada'.

Quando indagados a respeito de se 'Houve mudança na qualidade de ar durante ou após a conclusão da obra', 56\% dos moradores responderam que sim, ressaltando ser para pior, e ainda notaram uma maior presença de poeira e incidência de doenças respiratórias. A geração de poeiras ou material particulado nos canteiros de obra e vizinhanças são decorrentes de diferentes etapas das obras de constrição civil. Dentre essas etapas, a que evidencia uma maior geração de partículas e a terraplanagem, cujo material componente é a terra, sendo este inerte, não trazendo problemas graves de saúde, apenas a possibilidade de alergias. $O$ diâmetro médio das partículas de terra é grande, o que reduz a agressividade à saúde. Contudo, a fase de obra bruta e acabamento possuem significativo potencial poluidor, em decorrência do grande número de atividades que colaboram para a subdivisão das matérias com diminuição do tamanho das partículas e que tem composição variadas. Os efeitos adversos do material particulado sobre a saúde das pessoas estão relacionados mesmo com baixas concentrações deste material (MORAES, 2015).

'Durante e após implementação da avenida, houve impacto na água fornecida', $50 \%$ dos entrevistados disseram que sim e 50\% disseram que não, em relação aos que disseram que a água sofreu modificações em sua qualidade, informaram que isso ocorreu principalmente durante a implementação, destacando-se as respostas como 'durante a obra a água tinha gosto diferente e cor amarelada, geralmente 
aos sábados a água só funcionava a noite', 'sim, amarelada. Alguns bichos apareceram na água como minhocas' e 'Ficou com cheiro forte e amarelada'.

A qualidade da água modifica-se por interferência com a qualidade das águas superficiais e subterrâneas, no qual ocorre principalmente durante a fase de construção, o que corrobora com os relatos dos moradores. Durante fase de implementação pode ocorrer o efeito do carreamento de sólidos, assoreamento da rede de drenagem, além da utilização de banheiros, cozinhas e refeitórios e outras estruturas de apoio às obras como as usinas de asfalto e centrais de britagem. Sendo possível, ainda vazamentos de cargas nas proximidades dos cursos de drenagem, impactando diretamente no abastecimento de águas subterrâneas e superficiais, fazendo que a água que chega nas residências com baixa qualidade (REZENDE et al., 2016).

Quando indagados se 'Houve impacto visual com a implementação das obras', o resultado mostrou que $80 \%$ dos moradores não sentiram impactos visuais e os $20 \%$ que mudança é visível pelo maior fluxo de veículos na área.

Na última pergunta questionou-se 'Como você classifica a implementação do prolongamento da João Paulo', o resultado obtido demonstrou satisfação por parte dos moradores em sua percepção, no qual $66 \%$ deles consideraram bom.

Nesse contexto ressalta-se que para construção de avenidas o projeto deve ser elaborado de forma que busque o mínimo impacto socioambiental para os moradores e a biodiversidade local, no qual o planejamento acompanhe medidas preventivas e mitigatórias necessárias a serem executadas às custas do empreendedor responsável, contribuindo para a efetividade de uma obra dentro dos padrões de desenvolvimento sustentável, que considera os impactos negativos e positivos, econômicos e sociais, advindos com o surgimento das mesmas.

\section{CONCLUSÕES}

O prolongamento da Avenida João Paulo causou benefícios e impactos ambientais durante toda sua fase de pré e pós implementação. Os moradores sentiram mudança da sensação térmica local, decorrente da supressão de vegetação existente, aumento de ruídos, visto que a avenida é local de escoamento de cargas e afins e ainda houve o aumento material particulado no ar. Por meio dos mapas confeccionados foi possível visualizar que o prolongamento da avenida ocasionou uma perda considerável de vegetação o que pode ter ocasionado o aumento na temperatura superficial no bairro.

Entretanto, em decorrência da melhoria na infraestrutura considerou-se positivo por partes dos entrevistados o prolongamento da avenida, outrossim um melhor planejamento em vista a minimização de impactos ambientais é necessário e deve compreender todas as fases de implementação de obras dessa magnitude.

\section{REFERÊNCIAS}

ABREU, N. J. A.; ZANELLA, M. E.. Percepção de riscos de inundações: estudo de caso no bairro Guabiraba,
Maranguape-Ceará. Revista OKARA: Geografia em debate, v.9, p.90-107, 2015. 
ANJOS, L. J. S. L.. Mudanças climáticas e a resiliência da Floresta Amazônica ao longo do tempo e espaço.

Dissertação (Doutorado) - Universidade Federal do Pará, Belém, 2017.

BAHIA, V. E.; FENZL, N.; LEAL, L. R. B.; MORALES, G. P.. Caracterização hidrogeoquímica e qualidade das águas na área de abrangência do parque estadual do Utinga/Belém (PA). Águas Subterrâneas, v.25, n.1, 2011.

BANDEIRA, C.; FLORIANO, E. P.. Avaliação de impacto ambiental de rodovias. Caderno Didático, v.8, n.1, 2004.

FEITOSA, S. M. R.; GOMES, J. M. A.; NETO, J. M. M.; ANDRADE, C. S. P.. Consequências da Urbanização na Vegetação e na Temperatura da Superfície de Teresina/Piaui. Revista da Sociedade Brasileira de Arborização Urbana, v.6, n.2, p.58-75, 2019. DOI: http://dx.doi.org/10.5380/raega.v46i2.61224

MASHIKI, M. Y.; CAMPOS, S.. Geoprocessamento aplicado na influência do uso e ocupação do solo na temperatura aparente da superfície no município de Botucatu/SP. Energia na agricultura, v.28, n.3, p.143-149, 2013. DOI: http://dx.doi.org/10.17224/EnergAgric.2013v28n3p143-149

MEIRA, G. R. N.; TEIXEIRA, G. G. M.; VENTURIN, P. R. F.; GOTTSTEIN, P.; CAXAMBU, M. G.. Avaliação qualiquantitativa de espécies arbóreas no perímetro urbano da cidade de Corumbataí do Sul/PR. Revista da Sociedade Brasileira de Arborização Urbana, v.10, n.4, p.36-49, 2016.

MORAES, R. J. B.. Avaliação da emissão do material particulado proveniente de canteiros de obras habitacionais na fase de estruturas e alvenaria. Dissertação (Mestrado) - Universidade Federal da Bahia, Salvador, 2015.

MOREIRA, F. S. A.; VITORINO, M. I.. Relação de áreas verdes e temperatura da superfície para a cidade de Belém. Papers do NAEA, v.369, p.1-25, 2017.
MOURA, V. R.; MELO, G. D. S. V.; SANTOS, W. S.. Ruído e configuração espacial urbana: um estudo de caso na cidade de Belém do Pará. PARC Pesquisa em Arquitetura e Construção, v.7, n.4, p.237-251, 2016.

OLIVEIRA, T. T. G. T.; BEZERRA, P. E. S.; PONTES, A. N.; MARTINS, A. C. C. T.. Modificações paisagísticas e implicações térmicas no distrito administrativo de Belém, Pará. Revista Verde de Agroecologia e Desenvolvimento Sustentável, v.13, n.3, p.404-411, 2018.

PEREIRA, F. S.; VIEIRA, I. C. G.. Expansão urbana da Região Metropolitana de Belém sob a ótica de um sistema de índices de sustentabilidade. Revista Ambiente \& Água, v.11, n.3, p.731-744, 2016.

REZENDE, E. N.; COELHO, H. A.. Impactos ambientais decorrentes da construção de estradas e suas consequências na responsabilidade civil. Revista do Mestrado em Direito da Universidade Católica de Brasília: Escola de Direito, v.9, n.2, p.155-180, 2016. DOI: http://dx.doi.org/10.18840/19808860/rvmd.v9n2p155-180

SILVA, M. P.; SILVA, D. S.. Avaliação de impactos ambientais em projeto rodoviário urbano: estudo de caso Americana/SP. Revista Ciência e Tecnologia, v.16, n.28-29, 2013.

SOUSA, L. V. F.; ALMEIDA, R. H. C.. Participação social e percepção socioambiental: análise dos impactos de prolongamento de via urbana, Belém, Pará. Revista Contribuciones a las Ciencias Sociales, v.1, p.1-12, 2018.

TONIN, M. L. K.. Edificações para criação de espaços acusticamente confortáveis no meio urbano. Conhecimento Interativo, v.12, n.1, p.203-217, 2018.

VASEEN JÚNIOR, I.. Medidas ambientais aplicadas para minimizar os impactos gerados na construção da avenida do ribeirão ponte grande na cidade de Lages/SC. Repositório de Relatórios-Engenharia Civil, n.2, 2013.

A CBPC - Companhia Brasileira de Produção Científica (CNPJ: 11.221.422/0001-03) detém os direitos materiais desta publicação. Os direitos referem-se à publicação do trabalho em qualquer parte do mundo, incluindo os direitos às renovações, expansões e disseminações da contribuição, bem como outros direitos subsidiários. Todos os trabalhos publicados eletronicamente poderão posteriormente ser publicados em coletâneas impressas sob coordenação da Sustenere Publishing, da Companhia Brasileira de Produção Científica e seus parceiros autorizados. Os (as) autores (as) preservam os direitos autorais, mas não têm permissão para a publicação da contribuição em outro meio, impresso ou digital, em português ou em tradução. 